\title{
Research and Practice on Teaching Quality Control System For Undergraduate Programs on Information Based on Coordinated Management of Multi-platform Resources
}

\author{
Jiong Mu, Xuliang Duan,Jie Zhang \\ College of Information Engineering and Technology \\ Sichuan Agricultural University \\ Ya'an, China
}

\begin{abstract}
With the rapid development of information society, the demand for information technology talents has increased dramatically. At the same time, it has made higher demands on the quality of talents. At present, the training mode of information talents in our country is relatively simple, and the cultivation ability of practice is weak, It is difficult to adapt to the demand of the society . This research mainly through technical means, the quality of personnel training process to control, strengthen the training of links to enhance the quality of personnel training.
\end{abstract}

Keywords-Teaching Quality Control; Coordinated Management; Multi-platform

I. Research Background

Global informationization is not only one of modernization features in the 21 st century, but also an obvious feature of development of global economy and society. Informationization is bringing a deep revolution in the current world and playing an important role in reshaping the development layout of politics, economy, society, culture and military in the world. Fast development of the society has also accelerated increasing talent demand.

Colleges and universities are important bases of talent training and the teaching quality of colleges and universities has become a focus of the country, enterprises and even the whole society. How can we improve colleges and universities' talent training quality adapting to the demand of the society? Undergraduate education is the important and key point to improve the whole higher education.

At present, our country is in the stage of transforming from industrial society to information society. Innovation and upgrading of information technology industry and unceasing spring-up new technologies and new products have promoted a sharp increase of the society's demand quantity to skilled talents on information. Meanwhile, higher requirements for the quality of talents are also raised. It is the society's selection requirements for information talents to possess innovative ability and practical ability or not. [1]

\section{Research Contents}

\section{A. Problems existed in the training of information talents}

In the reality, firstly, information talents training mode in our colleges and universities is too single and homogenization of students' quality is also very serious, so it is very difficult for students to adapt to the market demand. Secondly, the characteristics 
of information majors are as follows: information is updated quickly and industrial demand is changed quickly. But in colleges and universities' major education currently, knowledge accumulation and teaching can't catch up with updating speed of the society's development demand any more. Necessary teaching reform is lack and course contents are far behind improvement speed of modern technology. All these have caused colleges and universities to be disjointed with the society, the industry and jobs on course setting, teaching contents, training mode and so on. Thirdly, teachers use the main teaching mode of lecture mostly to teach knowledge to the most extent and unilateral instilling is emphasized in the lecture. This has caused students' independent thinking ability, practical application ability and initiative innovative ability to be poor. Current teaching mode can't meet the demand of training high quality talents which possess innovative ability, practical ability and social competitive ability any more. Fourthly, examination and evaluation mode is single and a lot of stylized written examinations have caused students to not pay attention to daily learning accumulation but learn by rote and cope with examinations at the end of each semester. This is harmful for students to improve actual application ability. Fifthly, comprehensive practice is too few and the thinking set and working sluggishness of "emphasizing theories and neglecting experiments, emphasizing research and neglecting practice" is still existed in the teaching. This has limited students' learning initiative and creativity and restricted students' development of creation concept and innovative thinking ability. This kind of training trend has causes undergraduates to be unqualified for the requirements of working position.[2]

This research has mainly solved the following teaching problems: (1) it has solved the problems of insufficient practice and training in the former training scheme and disjointing of talent training with social demand; (2) it has solved the problem that students do not pay attention to daily learning accumulation but learn by rote and cope with examinations at the end of each semester; (3) it has solved the problem of disjointing of teaching with learning and less interaction and communication between teachers and students; (4) it has solved the problem of controlling students' daily study and sharing of various disciplines' excellent resources by making use of technical means; (5) it has realized separation of examination with teaching indeed and comprehensiveness and fairness of examinations by making use of computer-based examination platform. (6) it has solved the problem of insufficient cooperation depth and width between colleges and universities and enterprises. [3,4]

\section{B. Main research contents}

This program is to research how to improve education quality for undergraduate programs on information. To adapt to the development demand of modern society, the research is started from controlling every link influencing undergraduate education quality and realizes the goal of improving the teaching quality finally from points to surfaces. Depending on many teaching reform programs and based on training scheme, we establish the undergraduate education quality improvement system integrated with learning, examination and practical training with teaching teams supported by technical means.[5]

Newly established link control system (as shown in Figure 1).

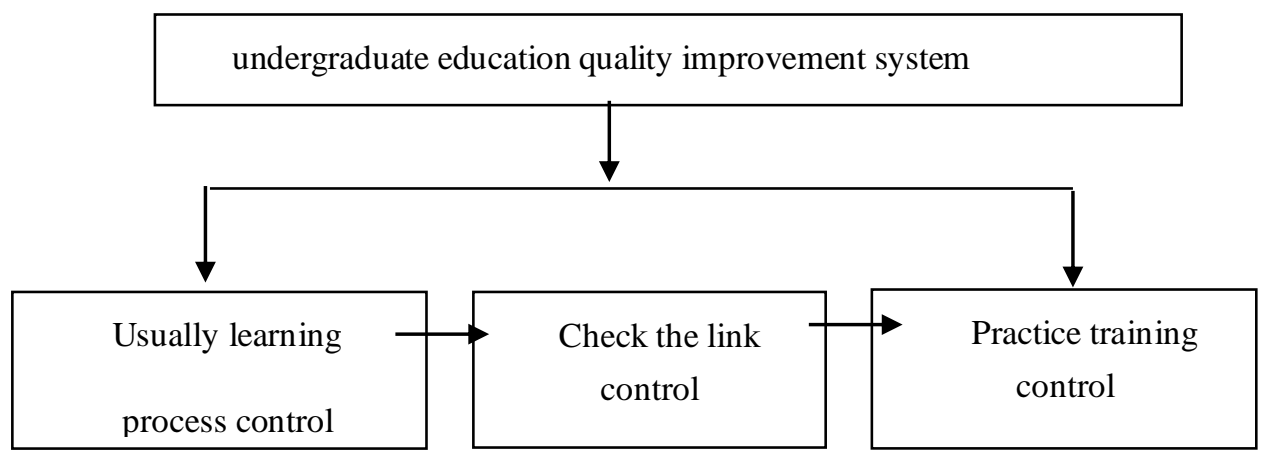

Fig. 1. Trinity of the link control system 
This research has realized the teaching quality improvement system paying attention to training students' practical ability with "link control + examination test+ practical training reinforcement" taking teaching in the classroom as a main line, supported by teaching team construction and depending on teaching reform programs.

\section{1) Learning process control link}

The training plan for majors is sorted and adjusted again according to the standard of the requirements of the Ministry of Education of the state oriented by the society's demand to talents and the course team is organized for all the major courses in the training plan, leading to finish the setting of learning link for every course. The team will conclude course contents into 3-5 learning stages according to the requirements of course outline, specify learning contents, supporting experiment program, daily exercise and qualified requirements in every stage, control students' learning process and ask them to meet corresponding requirements in every stage and then access to the test in this stage. Students will access to the next stage for learning after meeting the standards. The purpose is to strengthen students' daily learning and accumulation and enable learning process to be learned step by step. This process is carried out depending on Course Learning Platform developed by the team independently and realized the online judge system supporting programmed algorithm design courses such as "C Language Programming", "Data Structure" and "Analysis and Design of Algorithms" through exerting advantages of network platform, strengthening course process management and interaction between teachers and students and supporting course training with technical means. The application of this system has increased the code's judge efficiency and accuracy greatly, and integrated plagiarism testing function has effectively stimulated students to handle course tasks more carefully and precisely and played an active role in improving experiment teaching quality. Based on students' classified mutual evaluation system, we explore diversified evaluation system for students' academic performance, develop and complete students' course task self-help evaluation system based on Glicko, and transfer the main body of evaluation to student groups from teachers only with open, transparent, diversified and objective features. Furthermore, self-help evaluation system is a platform for student to communicate, use for reference and learn with each other further. In the actual application and implementation, students take part actively with careful attitude and the evaluation result is objective and effective and stimulate students' initiative effectively. Independently developed Virtual Laboratory platform is also mixed in Course Learning Platform. This part is divided into two modules and visualizes difficult points and important knowledge points in teaching, experimental facilities and links in the courses for software majors and hardware majors with the means such as videos, animation show and interactive operation, enriches excellent teaching resources to improve students' learning ability, and perfect preview link and experiment link. The modules of sharing of excellent course resources, hand-in and correction of online homework, automatic comparative analysis to similar homework and answering questions online are also integrated on Course Learning Platform. The construction of the platform can give full play to the role of teaching in the classroom and instruction after class, reduce teachers' management work quantity to daily learning greatly, establish good feedback system and interactive function and provide technical support for students in the control of learning process.

Implementation of this link has solved the problem that students do not pay attention to daily learning accumulation but learn by rote and cope with examinations at the end of each semester; it has solved the problem of disjointing of teaching with learning and less interaction and communication between teachers and students; and the problem of sharing of various disciplines' excellent resources; it has also reduced the teachers' work quantity on homework correction and analysis to similar homework greatly.

\section{2) Examination control link}

Examination link is one of important means to check students' learning status. We began to explore the computer-based examination from 2011 in this research and combined the examination mode of computer-based examination and separation of teaching from examination. Depending on teaching reform programs, we have completed the research and development of Computer-based Examination Platform over 1 year. The question bank is established to realize the function of automatic test paper and automatic paper inspection. The system took C Language Programming as a trial course in 2012 and held a formal examination joined by 160 persons. The examination process is successful and the correctness, usability and reliability of the system meet the 
requirements of design. Thereafter, computer-based examination system began to be promoted in the whole campus. Currently, construction of question banks for 143 courses has been completed. Course examination for 210,000 persons have been successfully completed with this examination system run in an orderly manner. Implementation of this system, has avoided disclosure of examination questions and students' behaviors such as selecting questions, guessing questions and cheating effectively and is favorable for students to master overall system of major knowledge and for teachers to organize and implement teaching according to teaching syllabus strictly, avoiding randomness of teaching contents. Generally speaking, computer-based examination has improved the level of separating examinations from teaching and justice and fairness of examinations and is favorable for construction of high quality teaching teams and training and improvement of students' self-learning ability and also has corrected examination style, learning style and campus spirit.

Implementation of this link has realized separation of examinations from teaching indeed, increased the quality of test paper, solved comprehensiveness and fairness of examinations and eradicated the problem of students' cheating in the examinations.

\section{Internship and practical training control link}

To realize the connection of training target with talent demand market, our faculty has employed experts and responsible persons from relevant institutions and enterprises to join in major construction, amended course contents of practical training in the training plan with the target of training innovative ability and practical ability and established scientific and reasonable practical teaching system. We pay attention to training students' ability in four aspects: 1) training of practical ability. We have established the target of practical teaching, paid attention to development of comprehensive and practical interdisciplinary training program and highlighted the training of occupational consciousness and practical ability; 2) training of innovative ability. Depending on students' scientific research interest program, innovative experiment program, double creation program and Challenge Cup, we have actively encouraged students to join in various kinds of innovative programs and developed students' innovative thinking and innovative ability; 3) training of self-learning ability. We have organized students to join in ACM Contest, Internet Innovation Contest and so on. Students' self-learning ability has been improved through many kinds of contests and learning exchange; 4) training of employment and career ability. We have expanded the cooperation programs between colleges and universities and enterprises, enhanced the development of practical training programs for enterprises, explored resources out of colleges and universities and provided employment and learning platform and career practice opportunities for students in colleges and universities. We have also guided students to set a correct employment and career view and established double career base for undergraduates. We have cooperated with enterprises and established Practical Training Platform for Student Internship. Through this platform, students can arrange and choose practical training programs, learn and submit practical training, share career programs and communicate and consult with each other on employment and career. It can enable students to know the demand of talent market in time, enhance cooperation and exchange with enterprises and set up the confidence on employment in advance.

Implementation of this link has solved the problems of insufficient practical training, disjointing of talent training with social demand and insufficient depth and width of cooperation between colleges and universities and enterprises in the former training plan.

\section{4) System assurance}

To enhance and promote the teaching reform, colleges and universities have issued a series of systems and policies to ensure improvement of teaching reform and teaching quality and provided guarantee and support from the aspect of systems.

The following figure is the framework of teaching quality improvement system for the whole information majors. 


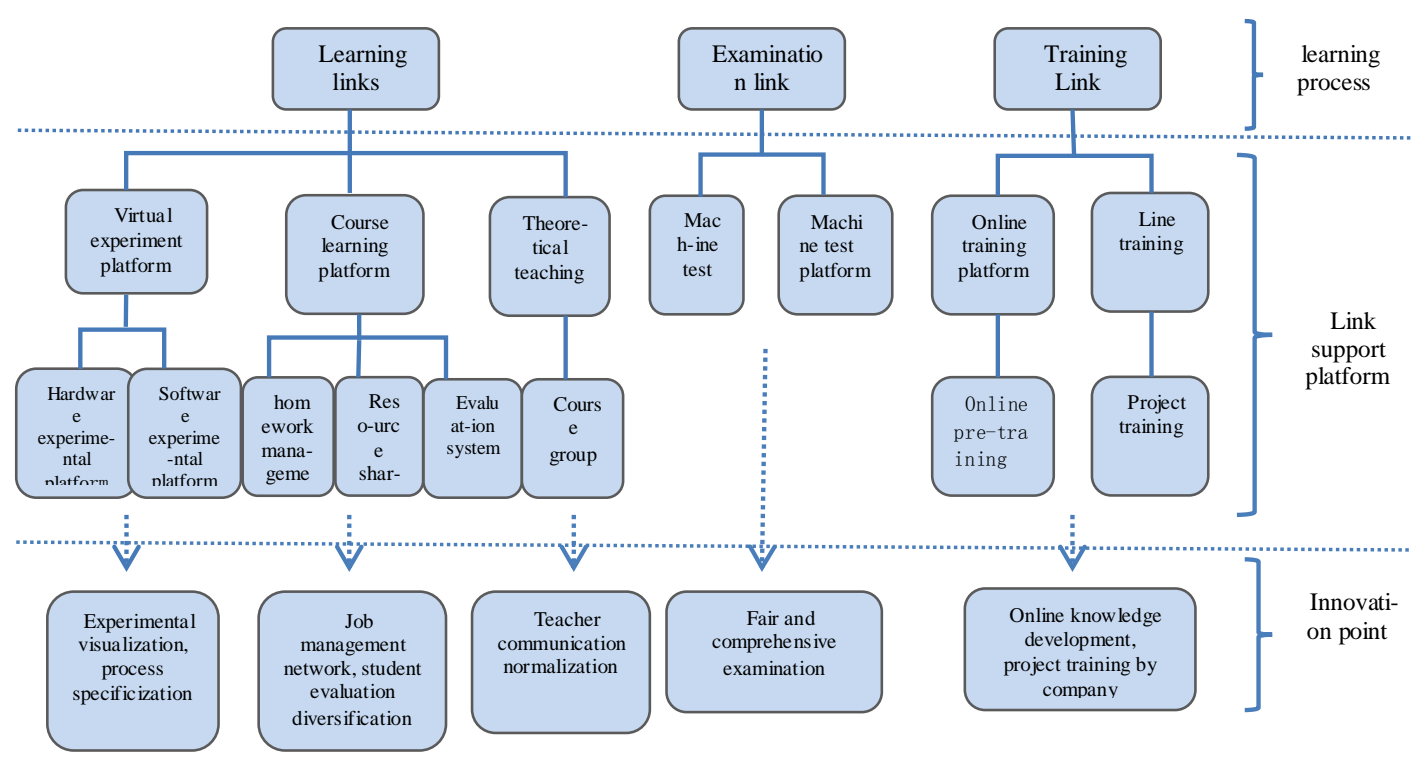

Fig. 2. Framework of Teaching Quality Improvement System

\section{Innovative points for the research}

\section{1) Innovation of teaching system}

Firstly, the training plan is improved guided by the society's demand to talents to enhance the reform of practical teaching system and enable students to apply what they have learned according to the target of training talents as required. Students are introduced to enterprises to join in practical training of courses so as to enhance training of their innovative ability and practical ability.

\section{2) Innovation of learning process}

Depending on course teams, every course is divided into 3-5 stages according to learning process. We control students' learning quality in every stage and monitor students' learning process. Every stage is composed of "learning in the classroom + daily training + interaction between teachers and students + examination in every stage". Overall teaching quality of courses is improved from points to surfaces by control of the quality in every stage.

\section{3) Innovation of quality monitoring technology}

A lot of information communication and interaction is existed between teachers and students in every link as learning process is composed of many links. This research team has developed Course Learning Platform, Virtual Laboratory Platform, Computer-based Examination Platform and Internship and Practical Training Platform independently by making use of major advantages, realized the monitoring management in the whole learning process under coordinated management of multi-platform resources, and provided technical support for improving teaching quality by making use of innovation of platform + network technology.

\section{4) Innovation of examination link}

Independently developed Computer-based Examination Platform can realize separation of examinations from teaching and from the test paper automatically according to teaching syllabus. Students can make the application for examination independently according to their own learning conditions and then the system will arrange examination time and place automatically and avoid cheating in the examinations and show fairness and comprehensiveness of examinations. It has been completely carried out in many majors in colleges and universities and realized the examination mode for 134 courses. 


\section{5) Innovation of practice}

Practical teaching is developed by making use of "online and offline practical training innovation mode". Online practical training means: learning development tools and basic knowledge expansion necessary for practical training through online guidance firstly. Offline practical training means: enterprises' entry to conduct intensive company management training "face to face" through offline practical training. Every major course is matched with practical training for a week and the major is matched with comprehensive practical training for 2 weeks before graduation. Before students step into the society, it will enhance the width and depth of internships and practical training, shorten the distance between students and social demand at best and strengthen students' ability to adapt to the society through training of actually developed programs by enterprises which connect with social demand closely. Since implementation of "online and offline practical training innovation mode" in the last two years, students' practical ability has been strengthened obviously and undergraduates' employment quality has been improved obviously with good praises from the society.

\section{6) Innovation of the system}

The colleges has issued a series of relevant policies for improvement of undergraduate education quality and ensure implementation of various teaching link reform from systems and motivation system.

\section{Research Effect}

Based on the support of various teaching reform programs, construction of course teams and construction of excellent and featured courses, we have developed Course Learning Platform, Virtual Laboratory Platform, Computer-based Examination Platform and Internship and Practical Training Platform according to design of information talents training system "link control + examination test + practical training reinforcement". We has improved teachers' ability to control students' learning process and link by making use of coordinated management of multi-platform resources. The system has benefited from the teaching affairs office's great support in the process of actual operation. We use it in some courses for trial firstly and then perfect and then enlarge management function in the use. From 2012-2014, we began to promote it in the whole campus after trial operation for over one year. Up to now, it has been implemented in many majors of the whole campus and gained good effect.

\section{1) Obvious effect of platform construction and application \& promotion}

We possess a teaching team with strong professional teaching ethics. They are active, innovative, diligent and solid in the work. Independently developed Course Learning Platform, Virtual Laboratory Platform, Computer-based Examination Platform and Internship and Practical Training Platform, have been perfected and promoted continuously in the application after practical application for over 2 years. Up to 2017, trial teaching have been accomplished in 340 classes through Course Learning Platform, over 1500 teaching tasks have been completed, and there are over 110000 files managing students' various daily trainings, over 1600 excellent resources shared, and 8900 students joining in the trial; 143 question banks for computer-based examination are established in Computer-based Examination Platform and 210,000 students have joined in the course examination system run in an orderly manner. There is 36 cooperation programs between colleges and universities and enterprises Internship and Practical Training Platform, 1514 students joining in practical training programs, 82 development teams established, 8387 lines of code quantity averagely for the team, 5 sets of learning materials for practical training, and 10 sets of development tools for practical training. 4 courses are listed into Virtual Laboratory Platform, and over 40 videos and interactive experiment programs are completed.

\section{2) Obvious improvement of students' innovative ability and practical ability}

Students have shown outstanding performance in publishing scientific research thesis, participation in textbook and works compilation and participation in scientific and technological contests with details as follows: 20 excellent graduation thesis from 2012 to 2017, and students joined in 11 innovation experiments for undergraduates (including 3 national programs), 34 scientific research interest programs, organized 3 professional skill contests, joined in various kinds of scientific and technological contents 
and obtained 25 awards at provincial level and above, published 2 scientific and technological thesis (EI) as the first author, joined in 12 applied or authorized patents, and joined in the compilation of 10 textbooks in the recent 4 years.

3) Enhancement of employment competitiveness and obvious improvement of talent training quality

In the recent 4 years, undergraduates in this college who are admitted to study the graduate programs of " 985 " or 211 colleges and universities account for over $95 \%$ of the number of admitted students. Employment rate in a lump sum comes to over $95 \%$ in the recent 4 years, and the rate of working for Top 500 listed companies, state-owned enterprises and institutions in the world is rising year by year, and job suited rate is over $90 \%$. Graduates have received good praises from employers due to their good quality and many of them have been awarded with the honorable titles of AAA Student, Excellent League Member, Excellent Student Cadre, Excellent Cadre of Communist Youth League of China, Excellent Graduate and so on.

\section{4) Obvious improvement of talent training foundation}

In Aug. 2013, we obtained the excellent engineer plan program from the provincial education department; in Mar. 2015, we obtained colleges and universities' key laboratory program on "agricultural information engineering" from the provincial education department; in June 2016, we passed the argument for the first class of subject base for "agricultural engineering" and then passed the second class of subject base for "agricultural information engineering" self-designed thereafter, and 1 important laboratory in the campus. The campus experimental teaching example center includes internship base in the campus for such majors as Computer Science and Technology, Internet Engineering, Information Management and Information system, Information and Computing Science, Agricultural Electrification and Automation and so on with a total area of $3049 \mathrm{~m} 2$. There are 24 internship bases out of the campus.

\section{Conclusion}

This research has been summarized and perfected continuously in the application after practical application for over 2 years. The teaching team regards undergraduate education quality management system integrated with learning, examination and practical training as guidance framework supported by technical means through the management mode of platform + network. This system has improved teachers' management ability effectively and created more learning channels for students; connected teaching with social demand effectively through practical training of company programs and increase students' enthusiasm and employment confidence; enhanced students' sense of responsibility for learning for themselves and enabled them to become the main body of learning. It's proved by practice that teaching quality control system based on coordinated management of multi-platform resources can bring good management and control effect to improvement of teaching quality for undergraduate students majoring in information and the teaching implementation framework designed by us is successful.

\section{Acknowledgement}

This paper was funded by Sichuan Agricultural University teaching reform project ,project name: Exploration and Application of Students' Mutual Evaluation Based on Ranking in Curriculum Assessment (X2015043), Reform and Practice of Computer Software Course Based on Micro - course(04052544).

\section{REFERENCES}

[1] YuanQiang Cai,HaiDong Dai,ZhiQiu Weng,The Confusion and Countermeasure Faced by Local Colleges and Universities, Research on Higher Engineering Education[J],1(2010)96-101.

[2] Feng Wang,JianGuo Tang,HongMei Zhang, Reflections on the Practical Teaching System of Electronic Information Courses in Colleges and Universities under the Background of Quality Education, The journal of educational reform to explore,4(2016)123-124.

[3] Hong Li, Reflections on the Application of Cloud Computing in the Teaching of Computer Specialty in Colleges and Universities, Journal of Anshan Normal University[J]. 06(2012) 57-63.

[4] Jie Yang, Yuan Chen, The Influence of Cloud Computing on the Construction of Informationalized Teaching Resources in Colleges and Universities, Information Technology and Informatization[J].07(2014)153-155.

[5] ShaoBin Wu,Training of computational thinking and programming capabilities, Computer education[J],16(2011)11-14. 